\title{
Object control interpretations with volitional verbs in infinitive complexes of Early Modern English
}

\author{
O. M. Tuhai \\ Borys Grinchenko Kyiv University, Ukraine \\ Corresponding author. E-mail: o.tuhai@ kubg.edu.ua
}

Paper received 30.09.19; Accepted for publication 14.10.19.

https://doi.org/10.31174/SEND-Ph2019-210VII61-14

\begin{abstract}
The study investigates object control interpretations with volitional verbs followed by infinitives of ditransitive and complex-transitive complementation in Early Modern English. The author argues that ditransitive and complex-transitive verbs of will are defined as predicates of direct and indirect speech which presupposes different transitive variations of syntactic infinitive clausal configuration. The article concentrates on case marking of overt object noun phrases of the matrix verbs in infinitive sentences with the main verbs of will. The research establishes particular diverse theta-grid paradigm of the infinitive ditransitive, complex-transitive complementation as of two or three argument arrangement.
\end{abstract}

Keywords: object control interpretation, infinitive complementation, predicates of direct/indirect speech, Early Modern English, volitional verbs.

Introduction. Syntactic research of non-finite clauses has been the topic for a vast enterprise discussion in scientific domains for more that fifty years. There has also increased the focus of semantic studies with the tendency to determine control relations by the lexical nature of the verbs within their scope. Traditional grammar identifies subject control from object control infinitive structures with respect to subject or object as a controlling element where control properties are defined by the meaning of the matrix verbs. Object control interpretation still provides significant results necessary for the analysis of generative syntactic patterns within infinitival sentences both in present-day English and in diachronic and synchronic studies. The research goal is to analyze syntactic characteristics of infinitives with volitional verbs in Early Modern English. The object of the paper is ditransitive and complex-transitive infinitive complements. The subject of the paper is object control peculiarities, case marking and argument structure of ditransitive and complex-transitive infinitival constructions. The tasks pursued in present study are the following ones: 1) to examine syntactic peculiarities of ditransitive and complextransitive infinitive complementation in Early Modern English; 2) to interpret object control features in infinitive constructions; 3) to analyze case marking assignment to the object NP; 4) to define theta roles and argument structure in sentences with infinitival complement clauses.

Basic publications and researches. In generative syntax infinitive constructions focusing on subject and object control have been an essential concern in plenty of researches. The study of different aspects of infinitive relations has been conducted by both Ukrainian (T. Kryvoruchko, M. Polkhovska, O. Ochkovska, H. Zinchenko) and foreign scholars (I. Landau, I. Sag, C. Pollard, B. Comrie, E. Gelderen, B. Los, K. Hale, J. Keyser, R. Huddleston, G. Pullum). In particular, Ukrainian scientists contributed to: the investigation of subject-to-subject and subject-to-object raising and control relations $-\mathrm{T}$. Kryvoruchko; the argument structure with raising and control verbs - M. Polkhovska, O. Ochkovska; subject properties in infinitives $-\mathrm{H}$. Zinchenko. Foreign linguists contributed their researches to: control relations with different lexical groups of control verbs - C. Pollard, I. Sag; subject and object control in general - B. Comrie; the relations in clause structure $-\mathrm{E}$. Gelderen, B. Los; the argument structure - K. Hale, J. Keyser, R. Huddleston, G. Pullum; structure and meaning in infinitival control constructions - I. Landau. But in linguistic studies concerning the issue of syntactic structural configurations and control properties with ditransitive, complex-transitive volitional verbs in the historical perspective, exactly Early Modern English, there exists a certain gap.

Material and methods. The text material under the present study is taken from W. Shakespeare and T. Middleton corpus data of the completed folio written works. The research volitional verbs such as request, beseech, pray, entreat, persuade, advise, instruct, appoint, force, enforce, compel, forbid, command, order, charge, require, induce, allow, permit, dare are chosen from the Roget's II: The New Thesaurus dictionary on the basis of the specific willing semantics of the verbs [15]. The present research is based on several methods and approaches according to the goal of the paper and the text material from Early Modern English. Namely, structural method is used to highlight certain syntactic units and combinations in an utterance, to outline the forms of syntactic relations and the surface structure of the infinitive sentences. The method of distributional analysis enables to investigate functional peculiarities of lingual constituents by way of studying their distribution in the constructions. Transformational-generative approach aims to characterize syntactic properties (object control, case marking, argument structure), to define origin of infinitive clauses within ditransitive and complex-transitive complementation by transformational rules application for distinguishing the relevant structures of the research infinitives in their configurations. The method of linguistic description involves exploring the language phenomenon of infinitive constructions with volitional verbs directly in the text.

Results and discussion. Ditransitive and complex-transitive infinitive complexes in EModE show a variety of syntactic configurations and properties with volitional verbs.In modern traditional linguistics ditransitive and complex-transitive complementation is actualized in to/bare- and wh- infinitive clauses where the main predicates take in their post position one or two elements depending on the transitive functions and valence of the verbs. Namely, ditransitive infinitive complementation is realized as direct object with indirect object by: a) to/bare-infinitive clause as SVOi (NP) Od (to/bare Inf) pattern, b) wh-infinitive clause as SVOi (NP) Od (wh- to Inf) model. Whereas complex-transitive infinitive complementation is considered as predicative complement with direct object by: a) to-infinitive clause as SVOd (NP) Compl (to Inf) model, b) bare-infinitive clause as SVOd (NP) Compl (bare Inf) pattern [12, p. 1171].

According to the Control Theory which presupposes that subject or object control in the infinitives depends on the lexical 
semantics of the main predicates the research verbs of will from our corpus data are postulated as object control verbs with the following lexical types [11, p. 286-287]:

1) request/advise type - verbs of requesting and advising such as request, beseech, pray, entreat, persuade, advise, instruct; 2) order/permit type - verbs of ordering and permitting such as appoint, force, enforce, compel, forbid, command, order, charge, require, induce, allow, permit, dare.

Accordingly, in present paper the author claims that control properties and lexical nature of the volitional verbs determine object control and the particular type of complementation, that is either ditransitive or complex-transitive infinitive construction.

Syntactic properties of ditransitive infinitive complementation. Ditransitive complementation is characterized by ditransitive verbs of will as request, entreat, persuade, forbid, command, instruct, advise that open two argument positions to be filled in order to enlarge and complete the main predicates semantics. Special peculiarities of this nonfinite infinitive complementation is that verbs of will can introduce both indirect directives and indirect questions. Traditional grammar describes the research ditransitive volitional verbs as those ones that bring in indirect speech where the object correlates with the addressee [12, p. 1203-1215]. In functional syntax an accusative case is associated with direct object, but in case of the indirect speech predicates an object is a person to whom the action is purposed indirectly. This particular feature designates the very important morphological peculiarity of the research ditransitive type of infinitive complementation, precisely the assignment by the matrix volitional verbs an accusative case to the indirect object that stipulates differentiations in their generation in dynamic synchrony.

Moreover, it should be reminded that ditransitive volitional verbs of command, permission, inducement, persuasion and request already occur in Middle English within the object control constructions where an object noun phrase correlates with the recipient both in dative (verbs of commanding) as well as in accusative (verbs of persuading). But in Early Modern English it is witnessed a considerable marked increase of similar constructions in which a NP object is no longer a recipient of the main predicate, although being still case-marked by that higher verb and being received its theta-role from the to-infinitive $[8, \mathrm{p}$. 240-242]. As G. Curme points out, in the course of English language development object modifiers of accusative and dative cases had lost their specific forms that could be identified only by the sentence word order or through the semantic features of the verb [3, p. 132]. Hence, the author presumes that the object NP in ditransitive infinitive complementation is not case-marked by the dative, but by the accusative case. In spite of this, during Early Modern English in Accusativus cum Infinito constructions with above mentioned ditransitive verbs of will it is witnessed more frequently usage of not only pure to-infinitive but the predicate's object person to whom the action is referred considering him as an addressee or an infinitive subject in an accusative case [9, p. 22-23]. Therefore, the author considers ditransitive verbs of will as predicates of indirect speech with an indirect object NP or an infinitive subject as a recipient/addressee in an accusative case.

In EModE the basic configuration of ditransitive infinitive complementation is defined as SVOiOd model - subject, predicate, indirect and direct objects with three argument structure. Hence, it is divided two typological groups of predicative infinitive complementation, namely:

1. SVOi(NP)Od(to/bare Inf) - subject, predicate, noun phrase as indirect object and infinitive clause with/without particle to as direct object.

2. SVOi(NP)Od(wh- to Inf) - subject, predicate, noun phrase as indirect object and $w h$-infinitive clause with particle to as direct object.

The first configuration of ditransitive infinitive complementation is $\mathrm{SVOi}(\mathrm{NP}) \mathrm{Od}($ to/bare Inf) model. It is outlined as indirect object and to/bare infinitive of such volitional verbs: request, entreat, persuade, forbid, command.

(1) Coriolanus: 'And wrath o'erwhelm'd my pity: I request you To give my poor host freedom' (Shakespeare, Coriolanus, i, ix, 86) [16, p. 2098].

Example (1) evidences three argument structure of $\mathrm{V}$ request which assigns the cases and thematic roles to two arguments, namely the nominative case to its external argument subject NP $I$ as the agent of the action and the accusative case to the internal argument object NP you as the recipient of matrix action and the agent of the infinitive to give. The second internal main predicate actant is the infinitival clause VP To give my poor host freedom with the theta-role of a patient. Thematic role model of sentence (1) is designated as 'agent - addressee (recipient)/agent - patient'.

The following tree-scheme (2a) represents generation of example (1):

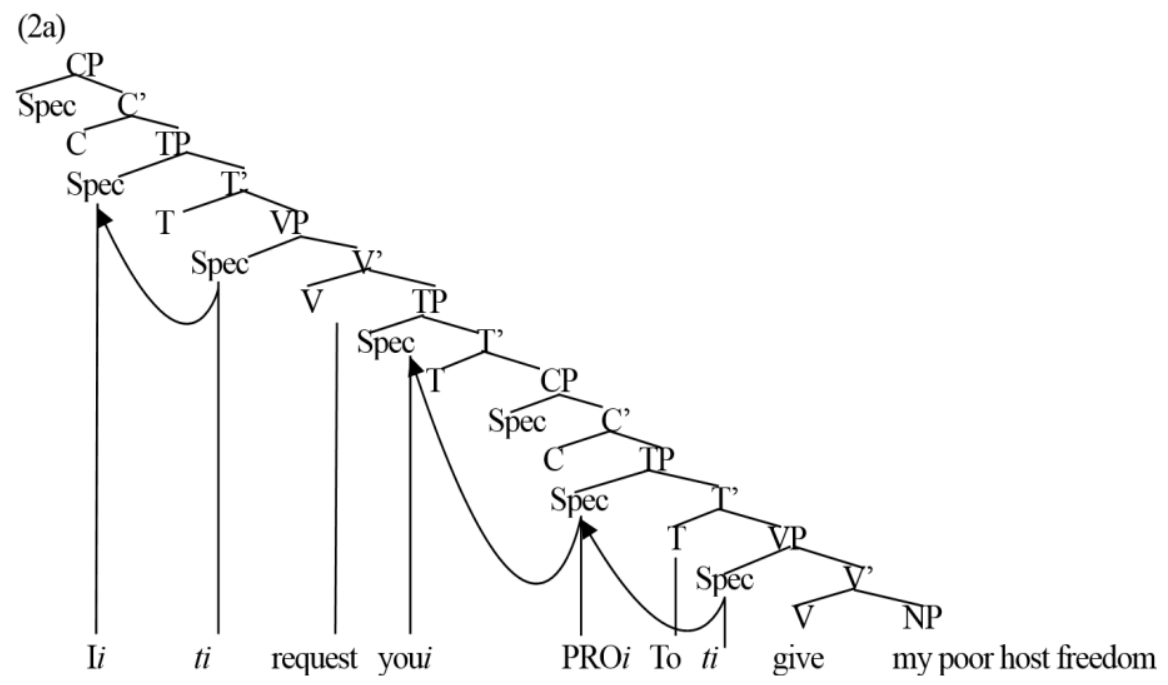

Significant diversity of sentence derivation (2a) is that the infinitival subject PRO after its origin in [Spec, VP] of the lower 
verbal projection moves through the co-indexed trace $i$ [Spec, $\mathrm{TP}]$ only to the matrix V request object position NP you [Spec, $\mathrm{TP}$ ] which happens to become an empty category antecedent and, hence, controls PRO. To satisfy the main grammatical requirement of the subject occurrence in every sentential clause the matrix subject NP I moves to location [Spec, TP] of the higher superordinate clause. Due to the semantic matrix verb features as of an object control and indirect speech predicate the matrix object NP you as the direct recipient of the main action controls PRO and appears to be the infinitive subject.

It is remarked that Objective Infinitive occupies the third actant position in combination with the second actant exclusively in an accusative case [18, p. 437]. Consequently, in sentence (1) V request assigns an accusative case to the whole infinitival clause To give my poor host freedom as its third argument as well as to the matrix object NP you that is the diverse special feature of such ditransitive complementation pattern in EModE where both an indirect object and the infinitive as a direct object obtain similar case, namely an accusative case, that is stipulated by the verbal volitional nature and determination of infinitive complexes with volitional verbs as Accusativus cum Infinito constructions in the research period.

Surface structure of example (1) may be shown in the following way:

(3a) $[\mathrm{CP}[\mathrm{TP}$ I $i \mathrm{VP}$ ti request $[\mathrm{TP}$ you $[\mathrm{CP}[\mathrm{TP}$ PRO $i$ To $[\mathrm{VP}$ $t i$ give [NP my poor host freedom]]]]]]]].

In next examples (4) - (7) from our corpus data it is determined three actant structure of infinitive sentences with volitional verbs and the object control of the infinitive subject PRO.

(4) Regan: 'If you will come to me, - For now I spy a danger, - I entreat you To bring but five and twenty: to no more Will I give place or notice' (Shakespeare, King Lear, ii, iv, 250-252) [16, p. 1909]. (5) Bassanio: 'Notwithstanding, use your pleasure: if your love do not persuade you to come, let not my letter' (Shakespeare, The Merchant of Venice, iii, ii, 334-335) [16, p. 313]. (6) Banquo: 'you should be women, And yet your beards forbid me to interpret That you are so' (Shakespeare, Macbeth, i, iii, 45-46) [16, p. 1958]. (7) Petruchio: 'Sirrah Gromio, go to your mistress; Say, I command her come to me' (Shakespeare, The Taming of the Shrew, v, ii, 95-96) [16, p. 169].

The second configuration of ditransitive infinitive complementation as SVOi(NP)Od(wh- to Inf) model is represented from our corpus text material with such verbs of will as advise, instruct. Specific characteristic of this model is an indirect object in the immediate post position of the main predicate along with $w$-element which introduces an infinitive clause that stipulates its interrogative type and determines some derivation peculiarities.

(8) Belarius: 'Stoop, boys; This gate Instructs you how to adore the heavens and bows you To a morning's holy office' (Shakespeare, Cymbeline, iii, iii, 2-3) [16, p. 2293].

Sentence (8) is characterized with three argument arrangement of matrix verb V Instruct that assigns to NP This gate as its external argument a nominative case and a theta-role of an agent, and to its indirect object NP you as the internal argument an accusative case with the thematic role of the addressee. Implicit infinitive subject PRO of V adore takes its own case from flection to because the main predicate can not assign case to PRO due to the intervening projection $\mathrm{CP}$. Infinitive clause how to adore the heavens is described as the second internal or the third argument of the matrix verb with an accusative case and a patient theta-role. Thematic role paradigm of sentence (8) is defined as 'agent - addressee (recipient)/agent - patient'.

Derivation of sentence (8) is outlined in the next tree-scheme (9a):

(9a)

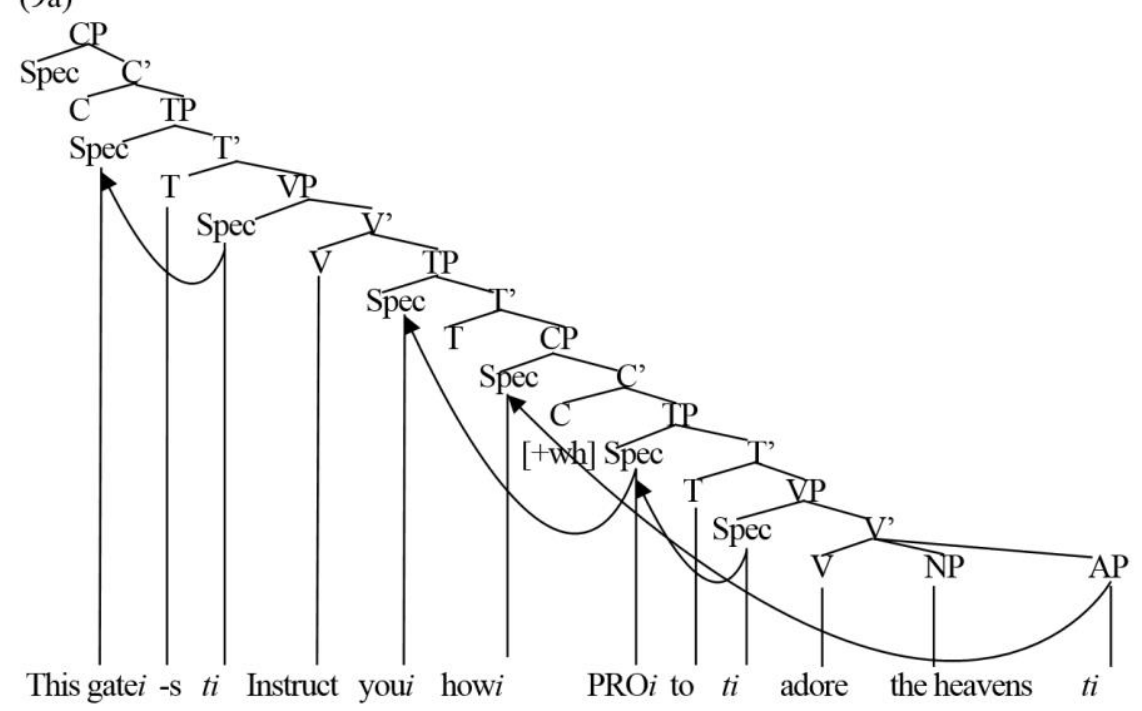

In scheme (9a) it is defined origin of principal and embedded clauses subjects NP This gate and PRO in specifier location of their VPs [Spec, VP] respectively. To check the nominative case feature NP This gate moves to the higher clause [Spec, TP] position whereas infinitive subject PRO moves first to [Spec, TP] location of CP projection for null case obtaining from flection particle to in [T, T'] due to referential relationship with its specifier in $[\mathrm{Spec}, \mathrm{TP}]$ of the lower clause. For controlling function PRO further moves up left to its landing site in V Instruct object position of NP you that occurs to become an antecedent of the trace $t i$ in canonical situation [Spec, VP] and controls the implicit infinitival subject PRO. The main distinction of example (8) generation is that complementizer how occupies the specifier position in [Spec, $\mathrm{CP}]$ of functional projection $\mathrm{CP}$ through the way of its origin in basic placement [AP, VP] of the adverbial infinitive object of $\mathrm{V}$ adore and movement further up left to the particular location in [Spec, CP] to check an interrogative feature [+wh] of $\mathrm{CP}$ complementary 
sentence. This interrogative sign $[+w h]$ is already realized in the head position [C, C'] of the complementary phrasal projection $\mathrm{CP}$ and is assigned by its specifier head after the spelling out operation. Relationship between the specifier and wh-phrase is designated as antecedental with complementizer how controlling and governing its own trace ti in [AP, VP]. Thus, whelement moves to location [Spec, $\mathrm{CP}$ ] for its phonological spell out utterance.

Surface structure of example (8) may be shown in the following way:

(10a) [CP [TP This gate $i$-s [VP $t i$ Instruct [TP you [CP how [TPPRO $i$ To [VP $t i$ adore [NP the heavens]]]]]]].

Next example (11) represents the infinitive construction of the subtype SVOi(NP)Od(wh- to Inf) with the volitional verb advise. Its syntactic structural generation is similar to the sentence tree-scheme (9a) with the verb instruct.

(11) Machbeth: 'I will advise you where to plant yourselves acquaint you with the perfect spy o'th' time' (Middleton, The Tragedie of Mackbeth, iii, i, 129-130) [17, p. 1182].

Hereby, infinitive constructions of ditransitive infinitive complementation are characterized as structures of three argument placement of the matrix verbs of will as predicates of indirect speech with an indirect object NP and an infinitive complement in the function of a direct object of declarative and interrogative nature. The main peculiarity of such complex infinitive sentences formation is their designation as structures of object control of infinitive subject PRO and matrix volitional verbs subcategorization by an indirect object NP in an accusative case that occurs to become their distinctive feature from other Accustivus cum Infinito constructions with other verbs. The basic thematic role paradigm of such object control infinitive constructions is represented as 'agent - addressee (recipient)/agent-patient'.

Syntactic peculiarities of complex-transitive infinitive complementation. In our research complex-transitive infinitive complementation of volitional verbs such as appoint, force, enforce, compel, induce, require, permit, allow, dare is considered by adding a direct object NP and to/bare infinitive clause. Theoretical linguistics represents such complementation pattern like SVOCo model where the infinitive complement clause is semantically adverbial and functions as a predication adjunct. The last one does not have its own explicit subject but only an implicit subject which may be actualized by an object of a superordinate sentence [12, p. 1202-1203]. Notably, dependent additional clauses exceptionally rarely function as conjunctions, object complements or indirect objects. As object complements they must be realized by non-finite clauses in complex-transitive complementation [13, p. 315]. In this aspect functional definition of the infinitival complement occurs to be controversial because it influences the clear actant structure description of the investigated complex-transitive infinitive construction as either of two or three arguments. Hence, there arises the following question if the infinitive clause within a complex-transitive complementation of verbs of will should be regarded as a predication adjunct or a complement. To clear this issue it is reasonable to discuss the principal leading syntactic characteristics of an adjunct and a complement.

In theoretical grammar an adjunct is considered as an element that can not be an argument of a verb [10, p. 81] Adjuncts are referred to the components that contain information about time, manner, cause, place, modality of the actions or states in a sentence. Adjuncts can not subcategorize verbs and, consequently, they do not act as arguments. The relationship between an adjunct and a verb is less direct than between a verb and its arguments which are connected with the latter one thematically [4, p. 29]. Additionally, an adjunct can be structurally absent in a sentence. Its presence does not depend on any other sentence constituent whereas existence of all verb's arguments is the crucial obligatory condition of any grammatically correct sentence formation [10, p. 82]. In this aspect the author argues that a complement can not be eliminated from a sentence structure since it supplements a verb and determines semantic implementation of the utterance meaning. Therefore, the author's arguments are grounded on the generative grammar analysis. Thus, theta-criterion sets 'one-toone' correlation between arguments and thematic roles, namely each argument bears one theta-role and each theta-role is assigned only to one argument $[5$, p. $54 ; 1$, p. 36]. As long as a verb functions as a semantic core of a sentence its meaning presupposes the quantity and theta-roles types which a verb prescribes to its arguments. In theta-role theory a verb can allocate one, two or three thematic roles that must be conformed with the appropriate arguments in a clause where the latter ones are realized by the verb's subject and complements [4, p. 29-44].

Unlike an adjunct which is joined to the maximal verb's position a complement is encompassed into the higher category phrase VP and can originate inside its hierarchically lower VP as an internal argument of a matrix predicate or within the projection V' framework as an external argument [10, p. 81-82]. According to K. Hale and J. Keyser's concept of lexical categories and projections each lexical head X determines an ambiguous projection of its category to the phrasal level XP and an ambiguous arrangement of its arguments as a specifier and a complement. Consequently, any appropriate VP may 'embed' as a complement of the verb [6, p. 149-156]. Thematic roles are assigned locally only to those arguments which syntactically occur in a clause that contains the verb [4, p. 44]. Complements occupy theta-positions and are marked respectively in each level in a projection scheme. Projection principle and conditions of the constituents marking provide their exceptional interpretation for satisfaction of the general condition on sentence phonological representation on a deep level and in a logical form [2, p. 48-49]. Hereby, an infinitive complement within the frame of the higher VP occurs to be in the actant position of the matrix verb.

All above mentioned diversity criteria for an adjunct and $a$ complement differentiation prove to become the grounds for identification of the infinitive clause syntactic function in a complex-transitive infinitive sentence as a verb complement that enables to define the investigated structural pattern as a three argument arrangement construction. So, in EModE the main configuration of complex-transitive infinitive complementation is represented by the following three argument placement model: SVOd(NP)Compl(to/bare Inf) - subject, predicate, direct object, predicative infinitive complement. It is divided into two groups depending on the occurrence of particle to, namely:

1. SVOd(NP)Compl(to Inf) - subject, predicate, NP as a direct object and an infinitive clause with particle to as a predicative complement.

2. SVOd(NP)Compl(bare Inf) - subject, predicate, NP as a direct object and an infinitive clause without particle to as a predicative complement.

In present research the first configuration of complextransitive infinitive complementation is determined as SVOd(NP)Compl(to Inf) model with volitional verbs of incomplete predication that demands verbal semantics 
completion of: causative verbs - force, enforce, appoint and the verbs of modal nature with such shades of will as permission, compulsion, obligation - compel, forbid, require, induce, allow, permit, dare.

It should be added that in the history of the English language infinitive constructions Accusativus cum Infinito with volitional verbs like require, permit, compel, induce and others evidence the tendency for taking a direct object NP in an accusative case where the investigated verbs are referred to the predicates of direct speech [9, p. 23; 12, p. 1202-1204]. These two criteria appear to become the crucial distinctive features of complextransitive infinitive constructions with verbs of will in Early Modern English period that differentiate complex-transitive infinitive complementation from ditransitive complementation with another ditransitive volitional verbs.

Let us consider origination peculiarities of infinitive sentences with complex-transitive verbs of will in EModE.

(12) Biondello: 'My master hath appointed me to go to Saint Luke's, to bid the priest be ready to come against you come with your appendix' (Shakespeare, The Taming of the Shrew, iv, iv, 102-103) [16, p. 162].

In example (12) it is witnessed that the verb appointed opens two positions to internal arguments: nominal phrase NP $m e$ in an accusative case as a direct object with theta-role of a patient and the infinitive clause to go. The external argument is the agent of the main action NP my master. It is reasonable to add that syntactic role of the patient is expressed preferably by a direct object and the agent causative verbs of three argument construction include one more agent that controls 'the embedded situation' which is 'caused' [19, p. 224-225]. This means that a direct object NP me occurs to become the patient of the main action and the agent of the infinitival action controlling the last one. Hence, sentence (12) is defined of three matrix argument arrangement with the thematic role paradigm as 'agent - patient/agent - patient'.

It is noted that syntactically three argument pattern of complex-transitive infinitive complementation coincides with the same model of ditransitive one, but semantically they differ by the main predicates meaning and the designation of valence characteristics of the second and the third actants. In generative grammar theta-roles are granted to predicate arguments through the operation of Merge with lexical categories. Thematic roles are assigned exclusively to lexical but not to functional categories [14, p. 166]. According to Ken Hale and Jay Keyser's theory of lexical categories and projections theta-role allocation occurs in the entire structural configuration. Thematic roles do not obtain formal features in a relevant sense. Typically they are assigned in the internal canonical base position or domain but not in the checking domain and hence they differ from the characteristics that are related to the $a$-movement theory [2, p. 287].

Derivation scheme (13a) syntactically represents semantic generation of example (12):

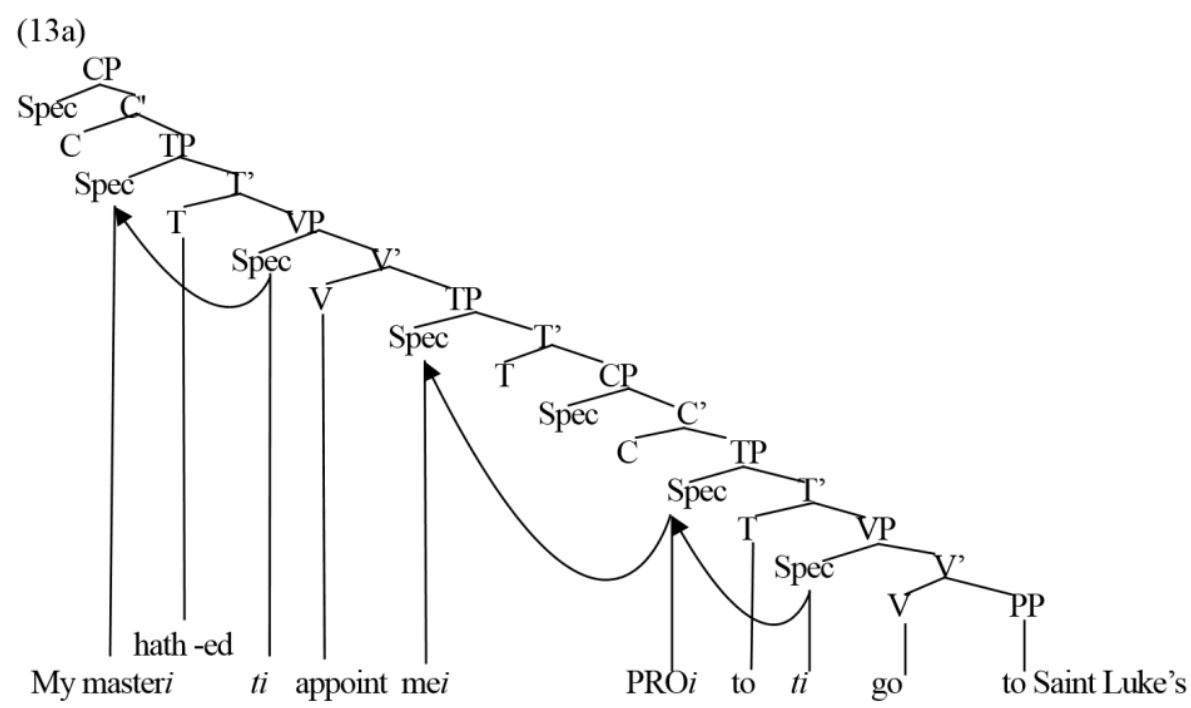

According to the hypothesis of subject internal origin in each verb phrase VP, infinitive subject PRO generates in the specifier position [Spec, VP] of the lower verbal projection VP and it is assigned the agent theta-role in the internal domain [Spec, VP] of the maximal infinitive clause projection VP. Infinitive go obtains the patient role in the shell [V, V', VP]. To check morphological case feature PRO moves to the specifier position of the tensed phrase [Spec, TP] and takes the null case from flection to. For obtaining the controlling function PRO moves further through the co-indexed trace $i$ to the matrix object position of NP me [Spec, TP] where the latter one becomes the antecedent of the empty category and hence controls PRO and the trace ti. Matrix subject NP my master originates in [Spec, $\mathrm{VP}]$ of the higher verb projection being allocated the agent role and then moves further to the higher clause location [Spec, TP] to take the nominative case. This feature also satisfies the demand of subject occurrence in each clause. Semantics of the main predicate $\mathrm{V}$ appoint as the verb of object control and direct speech designates infinitive subject PRO control by the direct object NP me which in the location of the verb appoint internal domain [Spec, TP] obtains theta-role of the patient of the superordinate sentence.

Next sentence pattern (14a) shows the surface structure of example (12):

(14a) [CP [TP My masteri [VP $t i$ appoint [TP me [CP [TP PRO $i$ to [VP $t i$ go [PP to Saint Luke's]]]]]]]].

Next examples (15) - (23) from the corpus of EModE writers demonstrate formation of infinitive complexes with three actant structure of volitional complex-transitive verbs of object control and direct speech. Represented sentences show similar generation peculiarities that were characterized in sentence (12) with the verb appoint.

(15) Antonio: 'You will compel me, then, to read the will?' (Shakespeare, Julius Caesar, iii, ii, 161) [16, p. 1705]. (16) Julia: 
'How angerly I taught my brow to frown, When inward joy enforced my heart to smile!' (Shakespeare, The Two Gentlemen of Verona, i, ii, 62-63) [16, p. 79]. (17) Escalus: 'but my brother justice have I found so severe, that he hath forced me to tell him he is indeed Justice' (Shakespeare, Measure for Measure, iii, ii, 267-268) [16, p. 726]. (18) Constance: 'How can the law forbid my tongue to curse?' (Shakespeare, King John, iii, i, 190) [16, p. 1118]. (19) Olivia: 'I heard you were saucy at my gates, and allowed your approach rather to wonder at you than to hear you' (Shakespeare, Twelfth Night, i, v, 209-211) [16, p. 518]. (20) Prince: 'Who doth permit the base contagious clouds To smother up his beauty from the world' (Shakespeare, King Henry IV, Part I, i, ii, 221-222) [16, p. 1160]. (21) Evans: 'and the letter is to desire and require her to solicit your master's desires to Mistress Anne Page' (Shakespeare, The Merry Wives of Windsor, i, ii, 11) [16, p. 457]. (22) Marcus: 'Grave witnesses of true experience, Cannot induce you to attend my words' (Shakespeare, Titus Andronicus, v, iii, 78-79) [16, p. 1601]. (23) Valentine: 'I dare thee but to breathe upon my love' (Shakespeare, The Two Gentlemen of Verona, v, iv, 131) [16, p. 114].

The second configuration of the predicative complextransitive infinitive complementation with zero infinitive marker of SVOd(NP)Compl(bare Inf) model pattern is represented by such complex-transitive verbs of will with the shades of permission, compulsion as enforce, force, forbid. The main distinctive feature of such infinitive complex sentences in Early Modern English period is the absence of marker to before the infinitive complement. It is remarked that in the process of the English language development and grammaticalization in the XVI-th century the usage of complementizer to with the infinitive tended to become a generally recognized rule $[7, \mathrm{p}$. 255]. Nevertheless, with some particular verbs, namely verbs of will, there occurred the tendency to its (marker to) omission. This grammatical phenomenon does not influence the sentence structure but it stipulates separate peculiarities concerning infinitive clause origin within the framework of a complex infinitive sentence.

(24) Silvia: 'Nor how my father would enforce me marry Vain Thurio' (Shakespeare, The Two Gentlemen of Verona, iv, iii, 16) [16, p. 106].

In example (24) the author evidences three argument arrangement of the main predicate enforce by three arguments: an external argument NP My father as the agent, the first internal argument NP $m e$ as the patient of the matrix action and the agent of the infinitive, the second internal argument VP marry Vain Thurio as the patient of the matrix verb. For case morphological features checking the subjects of the superordinate and the dependent clauses - NP My father and PRO respectively originate in their verb phrases specifiers positions [Spec, VP] and then move to locations in [Spec, TP]. PRO infinitive subject merges with NP $m e$ in domain [Spec, TP] where the last one becomes the antecedent of PRO and the controlling object of anaphora the trace $t i$. Thus, NP me controls PRO.

Derivation scheme (25a) of example (24):

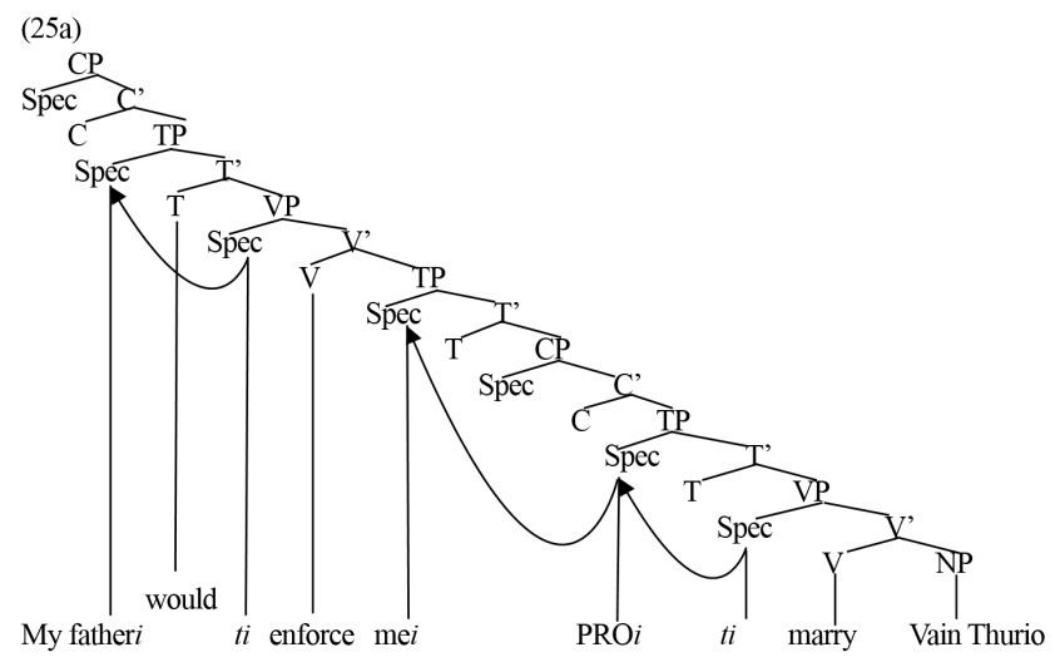

The main difference of sentence (24) formation is that under the Merge operation V marry combines with NP Vain Thurio forming intermediate V' and maximal VP projections which make the phrase marry Vain Thurio. The latter VP marry Vain Thurio merges with the empty head of infinitive flection $\mathrm{T}$ and forms projection T' which in its turn unites with PRO infinitive subject in [Spec, TP] and makes projection TP. Phonologically empty position of infinitive flection can not assign case to PRO that becomes unrealized and an implicit infinitive subject occurs caseless (zero case). Next consolidation of all sentence constituents leads to the combination of all higher elements through functional, intermediate projections and gradual generation of first the infinitive phrase me marry Vain Thurio, then verb phrases enforce me marry Vain Thurio, would enforce me marry Vain Thurio and at last the whole sentence My father would enforce me marry Vain Thurio.

Surface structure (26a) of example (24) is the same of sentence (12) and coincides with scheme (14a):

(26a) [CP [TP My fatheri [VP $t i$ enforce [TP me [CP [TP PRO $i$ [VP $t i$ marry [NP Vain Thurio]]]]]]]].

In the research period it is fixed analogous sentence constructions (27) - (28) with volitional verbs that show similar approach of derivational structure in terms of the Extended Standard Theory.

(27) Proteus: 'I'll force thee yield to my desire' (Shakespeare, The Two Gentlemen of Verona, v, iv, 59) [16, p. 113].(28) York: 'Peruse this writing here, and thou shalt know The treason that my haste forbids me show' (Shakespeare, King Richard II, v, iii, 49-50) [16, p. 1085].

Hereby, it is evidenced that in EModE sentences of complextransitive infinitive complementation are characterized as structures of three argument arrangement of the matrix volitional verbs as predicates of direct speech with a direct object in an accusative case and a predicative infinitive 
complement as an individual argument. These constructions are defined as structures of object control with thematic-role paradigm as 'agent - patient/agent - patient'.

Conclusions and perspectives. The results of syntactic analysis of object control interpretations in ditransitive, complextransitive infinitive complementation of volitional control verbs in EModE show their generated structures of object control with matrix predicates of direct and indirect speech. Infinitive clauses originate in the framework of a complementizer phrase $\mathrm{CP}$ governed by another predicate of a higher VP. Structural and semantic relations in projections of particular categories designate unambiguous constitutional relationships of ccommanding and complementation that prove complementary nature of infinitival clauses. Complementary infinitive clause predication is realized in the function of a direct object or a predicative complement. The research infinitive utterances evidence the tendency to appear with two or three argument placement due to transitive peculiarities and lexical nature of matrix verbs. In such infinitive control structures both direct and indirect NPs as an object are assigned an accusative case. Thetagrid paradigm with different semantic types of volitional verbs in Early Modern English is distinguished as 'agent - addressee (recipient)/agent - patient', 'agent - patient/agent - patient'. The findings of the study will contribute to the issue concerning the analysis of Early Modern English infinitival structures of ditransitive and complex-transitive complementation with verbs of will on the basis of new methods and approaches. Outcomes and data obtained in the present research are valuable as a constituent part of the comprehensive study of historical semantics and syntax of the verbs with volitional intention in Early Modern English period. Perspectives for further studies of infinitive complexes are considered in investigations of pragmatic types in infinitival sentences with volitional verbs in historical aspect.

\section{REFERENCES}

1. Chomsky N. Lectures on Government and Binding: the Pisa lectures / Noam Chomsky. - [7th ed.] - Berlin, New York: Mouton de Gruyter, 1993. $-371 \mathrm{p}$.

2. Chomsky N. The Minimalist program: 20th Anniversary Edition / Noam Chomsky. - Cambridge, Massachusetts, London, England: The MIT Press, 2015. - 393 p.

3. Curme G. O. English Grammar / George O. Curme. - New York, London: Harper and Row, 1947. -308 p.

4. Haegeman L. English grammar: A generative perspective / L. Haegeman, J. E. Guéron. - Oxford: Blackwell Publishers, 1999. $672 \mathrm{p}$.

5. Haegeman L. Introduction to Government and Binding Theory. Second edition / L. Haegeman. - Oxford, Cambridge (Mass.): Blackwell Publishers, 1994. -725 p.

6. Hale K. Lexical Categories and The Projection of Argument Structure / K. Hale, J. Keyser // Syntactic theory and Basque syntax. - San Sebastian: Gipuzkoako Foru Aldundia, 1992. - P. 147-173.

7. Kellner L. Historical outlines of English syntax / L. Kellner. - London, New York: Macmillan, 1905. - 336 p.

8. Los B. The Rise of the To-Infinitive / Bettelou Los. - Oxford, New York: Oxford University Press, 2005. - 335 p.

9. Maetzner E. An English grammar: methodical, analytical, and historical. Volume III / By Professor Eduard Adolf Ferdinand Maetzner. - London: J. Murray. Boston: Roberts, Brothers, 1874. $576 \mathrm{p}$.

10. Polkhovska M. V. Early New English Existential Sentences:

Structural, Semantic, and Functional Aspects / Maryna Polkhovska. Ph.D. dissertation, University of Zhytomyr, 2009. - 202 p.

11. Pollard C. Head-driven Phrase Structure Grammar / C. Pollard, I. A. Sag // Studies in contemporary linguistics. - Chicago: The University of Chicago Press, 1994. - 440 p.

12. Quirk R. A Comprehensive Grammar of the English Language / R. Quirk, S. Greenbaum, G. Leech, J. Svartvik. - London, New York: Longman, 1985. $-1779 \mathrm{p}$.

13. Quirk R. A University Grammar of English / R. Quirk, S. Greenbaum. - London: Longman, 1973. - 484 p.

14. Radford A. Syntax: A Minimalist Introduction / A. Radford. Cambridge, N. Y.: Cambridge University Press, 1997. - 283 p.

15. Roget's II: The New Thesaurus by the Editors of the American Heritage Dictionaries. - [3rd ed.] - Boston, New York: Houghton Mifflin, 1995. $-1200 \mathrm{p}$.

16. Rowse A. L. The annotated Shakespeare: three volumes in one illustrated: the comedies, the histories, sonnets, and other poems, the tragedies and romances. - New York: Greenwich House, 1988. $2479 \mathrm{p}$.

17. Taylor G. Thomas Middleton: The Collected Works / G. Taylor, J. Lavagnino. - [1st. ed.] - Oxford, New York: Clarendon Press, 2007. $-2016 \mathrm{p}$.

18. Tesniere L. Foundations of structural syntax: Translation from French / Lucien Tesniere. - M.: Progress, 1988. -656 p.

19. Testelets Y. Introduction to General Syntax / Y. G. Testelets. - M.: Russian State Humanitarian University, 2001. - 797 p. 